\title{
SISTEM PELACAK KENDARAAN BERBASIS OPENGTS
}

\author{
Rusnandar, Tedy Setiadi, Wahyu Pujiyono \\ Program Studi Teknik Informatika \\ Universitas Ahmad Dahlan Yogyakarta \\ leonandar@gmail.com, yywahyup@yahoo.com, tedz68@yahoo.com
}

\begin{abstract}
ABSTRAK
Sistem pelacak kendaraan merupakan implementasi dari sistem informasi berbasis lokasi. Sistem pelacak kendaraan sangat membantu dalam pengawasan dan pengamanan kendaraan dalam suatu perusahaan atau instansi.Dengan sistem pelacak kendaraan OpenGTS akan diimplementasikan sistem pelacak kendaraan pada sebuah isntansi atau industri yang memiliki perangkat pelacak GPS GT60, cakupan wilayah, fungsi sistem, dan manajemen sistem yang lebih khusus. Dari sistem yang diterapkan pada instansi atau industri dapat dikembangkan dalam pembuatan aplikasi dengan data dan sistem yang terintegrasi. Aplikasi yang dikembangkan menggunakan fungsi -fungsi Google Map API V.3 yang lebih difungsikan dalam penyajian pada peta.
\end{abstract}

Kata Kunci : Pelacak kendaraan, GPS, OpenGTS, Google MAP API v.3

\section{PENDAHULUAN}

Penerapan teknologi berbasis lokasi banyak diterapkan dalam berbagai dunia industri. Teknologi berbasis lokasi akan dapat mengetahui lokasi dari aset atau maupun barang komoditas industri. Selain meningkatkan keamanan juga akan meningkatkan mutu dari layanan barang atau jasa. Dalam keseharian teknologi ini dapat dilihat pada persewaan mobil, jasa tranportasi, jasa pengiriman barang. Dan masih banyak fungsi lain dari teknologi ini.

Sistem pelacak kendaraan merupakan salah satu dari teknologi berbasi lokasi. Banyak layanan berbayar sistem tersebut yang ditawarkan pada penyedia jasa atau industri. Selain itu sistem diberikan kepada pembelian produk baru dari perangkat pelacak kendaraan. Sehingga akan terasa mahal dan susah dalam pengembangan sistem.

Untuk mengatasi hal tersebut dapat dikembangkan sendiri sistem pelacak kendaraan yang berbasis OpenSource. Dengan program Opensource dapat dikembangkan dan di manajamen sesuai dengan kebutuhan industri atau instansi. OpenGTS merupakan program OpenSource sistem pelacak kendaraan.

Dalam penelitian ini akan mengimplementasikan sistem pelacak kendaraan OpenGTS. Sistem ini akan dimplementasikan pada perangkat pelacak GPS yang tersedia dipasaran dan dapat diterapkan pada suatu wilayah dan jenis usaha tertentu. Dari sistem yang telah diinstallasi dapat dikembangkan untuk aplikasi lain yang terintegrasi dengan sistem.

\section{KAJIAN PUSTAKA}

Pada kajaian terdahulu telah terdapat beberapa penelitian yang serupa tentang sistem pelacak kendraaan. Salah satunya penelitian yang berjudul Sistem Pelacak Kendaraan dengan Teknologi GPS dan GPRS[2]dalam penelitian tersebut dibahas bagaimana memanfaatkan teknologi GPS dan GPRS yang diterapkan dalam Software OpenGTS. Dari sisi hardwarepenelitian tersebut menggunakan device ESI Track H360 versi alat GPS Tracking Unit (GTU), Sistem pelacak kendaraan dengan teknologi GPS dan GPRS dipasang di sistem operasi windows XP SP2.

Pada penelitian lain yang berjudul Aplikasi Pelacakan Mobil pada Sistem Informasi Persewaan Mobil[9]mengimplementasikan perangkat berbasis Android sebagai GPS Tracking Unit dengan informasi lokasi memanfaatkan fasilitas LBS (Location Based 
Service). Bentuk penyajian data lokasi dengan peta digital dari Google Map API dengan penanda lokasi posisi terakhir.

Pada penelitian ini sistem pelacak kendaraan mengimplementasikan sistem pelacak kendaraan berbasis OpenGTS.Fungsi-fungsi yang diimplementasikan sistem pelacak kendaran meliputi penampilan informasi data lokasi dalam sajian peta dengan penanda berdasarkan kecepatan kendaraaan serta dilengkapi dengan rute kendaraan yang dilalui. Secara teknis pada penelitian ini menggunkan device GPS Portable GT60 sebagai perangkat pelacak GPS dan software OpenGTS menggunakan versi 2.3.9 yang berjalan di sistem operasi Linux

\section{A. OpenGTS}

OpenGTS merupakan implementasi dari komponen server dan pengolah data dalam komponen sistem pelacak kendaraan. OpenGTSTM (Open Source Tracking System)[4] adalah project OpenSource yang didesain khusus menyediakan Sistem Pelacak GPS berbasis web untuk armada kendaraan.Pada umunya armada kendaraan yang menggunakan sistem pelacak kendaraan seperti taksi, persewaaan mobil, pengiriman paket, dan transportasi umum baik milik pribadi maupun milik pemerintah.Untuk kode sumber dapat diperoleh pada laman http://opengts.org.

Pada versi 2.3.9 yang dirilis pada tanggal 6 Desember 2011, dapat diperoleh fitur-fitur lain selain mendukung pengumpulan data dan penyimpan data pelacakan GPS dan telemetri data perangkat jarak jauh sebagai berikut: otentikasi bebasis web, GPS independen, pengaturan layout halaman web, pengaturan layanan peta, pengaturan laporan, pengaturan geofencing area, dan Ii8n compliant. Untuk dukungan Perangkat pelacak GPS yang langsung dapat didukung OpenGTS meliputi:

1. Aspicore GSM Tracker (Nokia, Samsung, Sony Ericsson phones)

2. SanavGX-101 Vehicle Tracker, GC-101, MT-101, and CT-24 Personal Tracker

3. V-Sun 3338 Personal Tracker

4. GPSReader GPS data logger with automatic Wi-Fi upload, for in-cab Windowsbased computers.

5. Certain Boost Mobile phones (OpenDMTP compliant)

6. $\quad$ Android App "GPS2OpenGTS"

7. HP hw6965 Windows/CE phone (OpenDMTP compliant)

8. TAIP (Trimble ASCII Interface Protocol).

9. ZhongShan Technology Co, Ltd. "SIPGEAR" tracking devices.

10. Most TK102/TK103 tracking devices (those using the common TK102/TK103 protocols).

11. TrackStick GPS data logger

12. "GPSMapper" capable phones.

13. "NetGPS" capable devices.

14. iCare G3300 Personal Tracker.

15. Some Mologogo capable phones.

Untuk kebutuhan hardwareserveryang digunakan untuk tujuan pengujian[4], atau untuk melacak sejumlah kecil perangkat, konfigurasi minimum sebagai berikut CPU 1.8GHz,2Gb RAM, hardisk50GB, Ethernet adapterdan alamat IP Public. Namun untuk server dalam lingkungan produksi[4] dibutuhkan spesifikasi minimal yang lebih tinggi, berikut spesifikasi untuk lingkungan produksi: CPU 2.8 GHZ, RAM 8 GB, Hardisk 500GB RAID-1 array disk drive, gigabit ethernet adapter dan alamat IP publik.

OpenGTS sendiri dapat diinstallasi pada sistem operasi Linux, Windows, Freebsd, Openbsd, dan OS x. OpenGTS dapat berjalan baik, memerlukan dukungan program diantaranya: Java compiler, Apache Tomcat , Apache Ant, MySql Server, MySql JDBC Driver, JavaMail. Arsitektur Sistem OpenGTS dapat dilihat pada gambar.1 


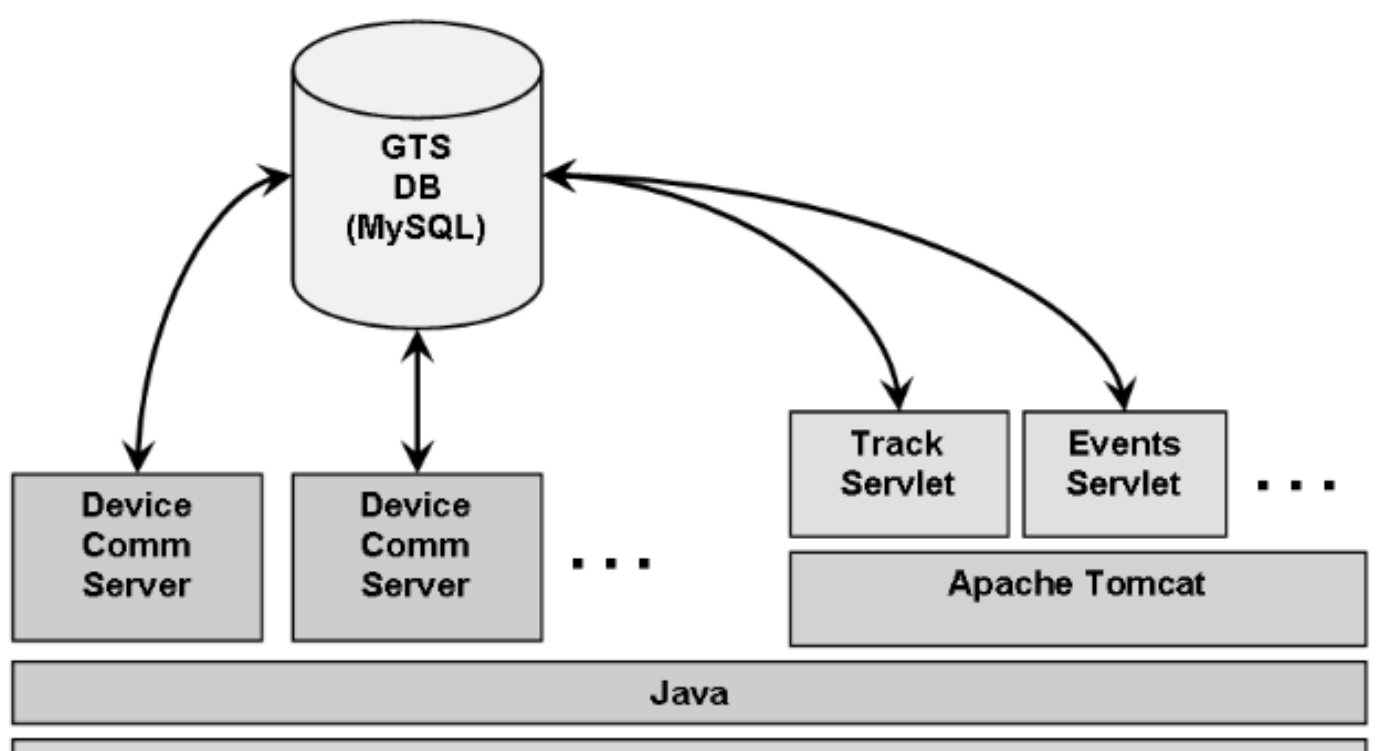

Operating System (Linux, Mac OS X, Windows, etc.)

\section{Gambar.1 Sistem Arsitektur OpenGTS}

\section{B. GPRMC}

NMEA 0813[5] adalah standard antarmuka mendefiniskan persyaratan sinyal listrik, transmisi data protokol dan waktu, dan format kalimat tertentu untuk databus serial 4800-baud. Data ini dalam bentuk ASCII yang dapat dicetak dan mencakup informasi seperti posisi, kecepatan, ketinggian lokasi, alokasi frekwensi, dll. Format NMEA 0813 banyak diimplementasikan untuk format komunikasi pada GPS dengan Server pengolah data lokasi.

Dalam GPS NMEA Sentence terdiri dari 19 format yang masing masing format memiliki fungsi dan spesifikasi penggunaannya, GPRMC merupakan salah satu dari 19 format data GPS NMEA, format data GPRMC dapat dilihat pada contoh berikut:

\$GPRMC,220516,A,5133.82,N,00042.24,W,173.8,231.8,130694,004.2,W*70

\section{GPS}

Global Positioning System atau yang sering disingkat dengan GPS merupakan teknologi penentu lokasi yang banyak digunakan saat ini. Dalam buku Sistem Informasi Geografis berbasis[8].GPS adalah suatu sistem radio navigasi penentuan lokasi mengunakan satelit. Dengan bantuan satelit akan diperoleh posisi yang akurat dan cepat dengan koordinat 3 dimensi $(\mathrm{x}, \mathrm{y}, \mathrm{z})$ ditambah dengan informasi waktu dan kecepatan bergerak. GPS pertama dikembangkan oleh Departemen Pertahanan Amerika serikat tahun 1973. NAVSTAR GPS merupakan nama lengkap dari GPS. Secara teknis GPS memilliki 3 Segmen utama yaitu: Space segement, control Segement, dan user segment.

\section{Perangkat Pelacak GPS GT60}

Perangkat pelacak GPS merupakan salah satu implementasi fungsi GPS sebagai penentu lokasi.Data lokasi pada perangkat pelacak GPS secara berkala dikirimkan ke server atau pengolah data yang merupakan bagian dari komponen sistem pelacak kendaraan. Data lokasi pada perangkat pelacak GPS dikirim dengan format data pelacakan(NMEA GPRMC), sedangkan untuk pentrasnmisian data lokasi ke komponen server atau pengolah data menggunakan jaringan seluler (GPRS atau SMS), radio atau 
modem satelit yang tertanam dalam perangkat tersebut. Pada gambar.2 dicontohkan implementasi perangkat penerima GPS pada sistem pelacak kendaraan.

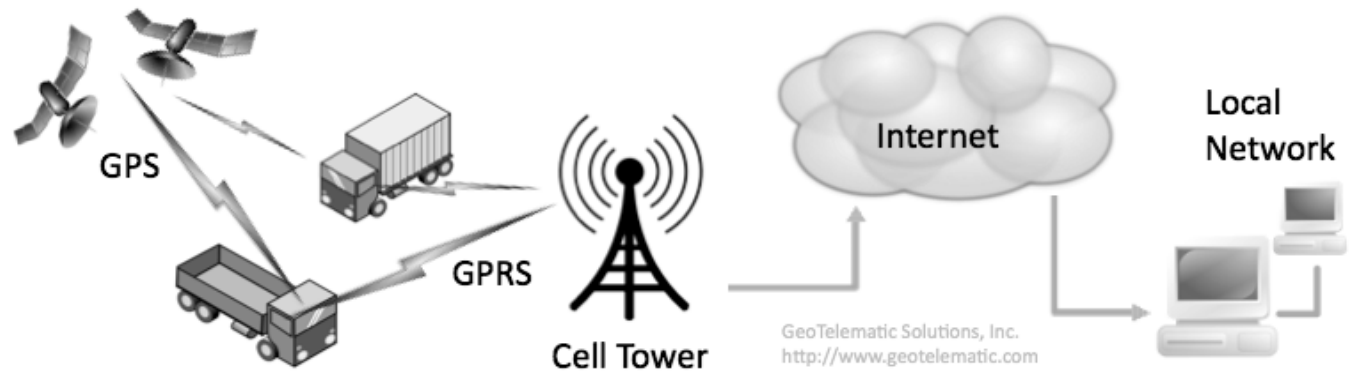

\section{Gambar.2 GPS pada sistem pelacak kendaraan[6]}

GT60 merupakan tipe perangkat pelacak yang dipasang pada orang atau barang, namun juga dapat diterapkan pada kendaraan. Perangkat ini memiliki GPS module untuk memperoleh informasi data posisi dan module GSM/GPRS untuk mengirimkan informasi data posisi ke telepon lain melalui SMS atau ke Server melalui data GPRS. Informasi data yang disampaikan ke server pelacak kendaraan dengan format NMEA 0183 GPRMC yang telah dijelaskan pada subab 2.2. GT60 dikonfigurasi dengan menggunakan SMS sehingga mempermudah dalam konfigurasi alat.

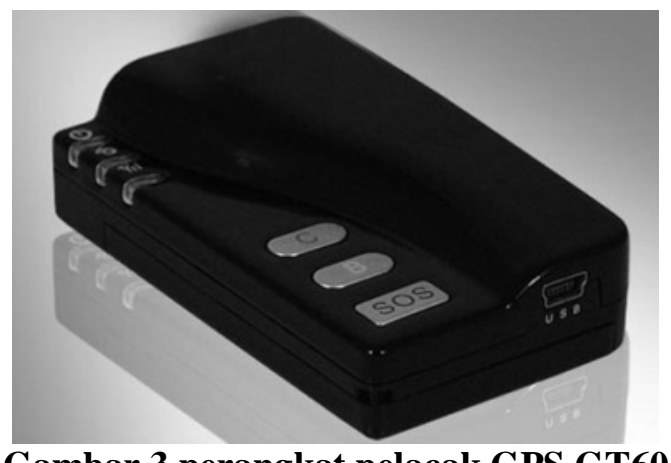

\section{Gambar.3 perangkat pelacak GPS GT60}

\section{E. Googlemap API V3}

Google Maps API v.3 merupakan aplikasi interface yang dapat diakses lewat javascript agar Google Map dapat ditampilkan pada halaman web yang sedang dibuat. Dengan google Maps API v.3 aplikasi yang dapat dibangun meliputi aplikasi berbasis lokasi, aplikasi mobile pemetaaan, menampilkan data geospartial data, dan pembuatan kustom pemetaan online[3].Pada Goole Maps AP V.3 banyak fungsi-fungsi baruyang tidak dijumpai pada versi sebelumnya. Contoh fungsi yang dapat dijumpai pada versi ini dan akan diimplementasikan pada penelitian ini adalah fungsi web serviceDirectionRoute dan TravelMode. Kedua fungsi inid digunakan dalam penyajian rute kendaraan yang pada dua titik sesuai dengan kondisi rute jalan sebenarnya, seperti terlihat pada gambar.4. Untuk contoh code dan contoh implementasis fungsi fungsi Google Map API V.3 dapat diperoleh pada laman.

https://developers.google.com/maps/documentation/. 


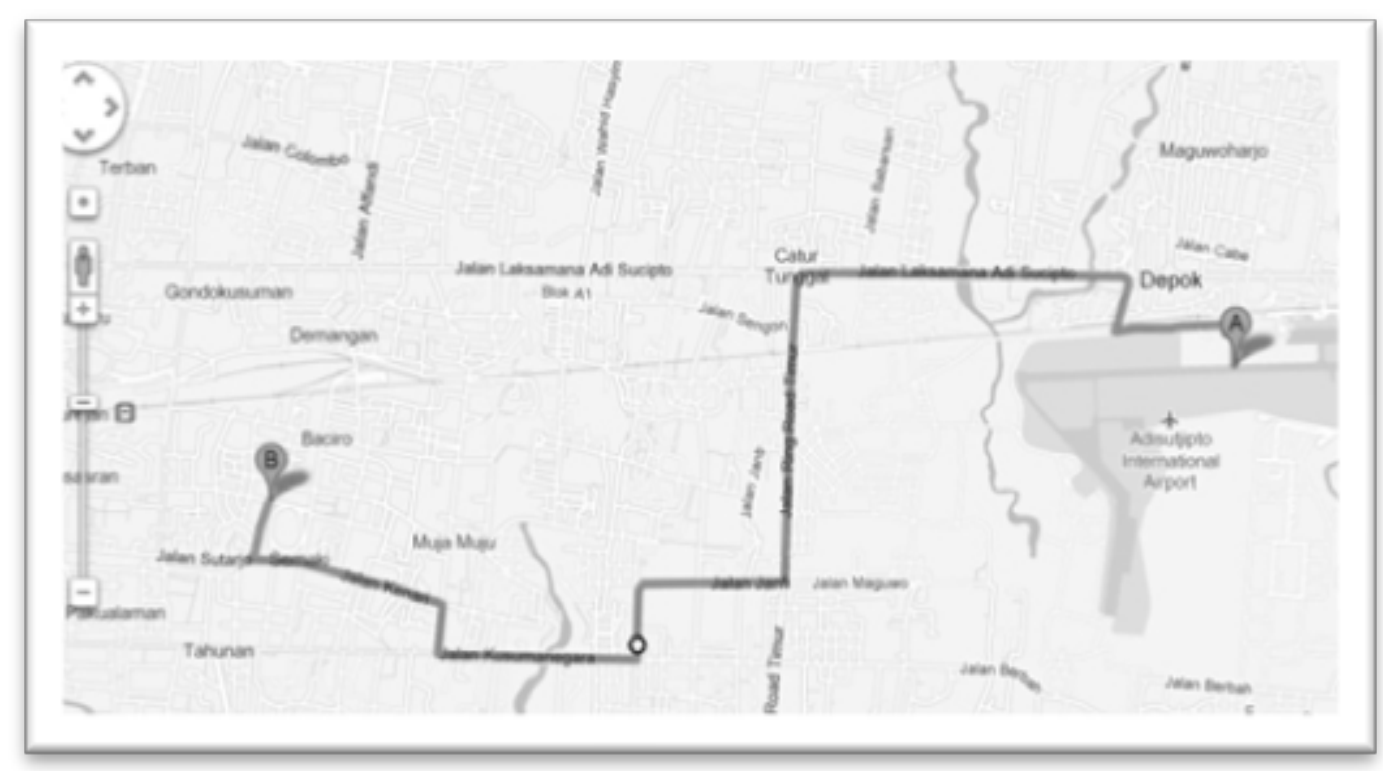

Gambar.4 hasil dari fungsi DirectionRouteGoogle Map API V.3

\section{METODE PENELITIAN}

Subjek penelitian yang akan dibahas pada tugas akhir ini adalah " Sistem Pelacak Kendaraan Berbasis OpenGTS” mengambil lokasi di PT. Panji Sekar Yogyakarta. Perusahaan tersebut bergerak dalam bidang jasa pengamanan. Pada penelitian ini objek yang akan diterapkan adalah kendaraaan operasional kantor.

Penelitian ini dilakukan dengan metode waterfall processmodelsebagai desain pengembangan sistem pelacak kendaraan yang diterapkan pada perusahaan. Dimulai dengan melakukan analisis kebutuhan sistem dengan studi wawancara, studi pustaka, dan observasi secara langsung. Dilanjutkan dengan melakukan perancangan sistem dengan menyesuaikan data yang diperoleh dari analisis data meliputi daerah operasional kendaraan, interval waktu pengiriman data ke server, pemilihan provider layanan seluler sebagai metode pengiriman data dan pemilihan spesifikasi server. Pada tahap perancangan ini ditentukan sistem OpenGTS sebagai sistem pelacak kendaraan berbasis Open Source. Tahap selanjutnya adalah implementasi sistem pelacak kendaraan berbasis OpenGTS diinstallasi pada sebuah VPS dengan sistem operasi Linux dengan program pendukung meliputi Java, Apache Tomcat, Apache Ant, MySql Server dan beberapa program pustaka Java. Untuk menghubungkan perangkat pelacak GPS GT60 perlu dilakukan modifikasi modul pada Device Comunication Server pada sistem OpenGTS. Penyajian data lokasi berupa peta digital dengan informasi kendaraan pada setiap titik lokasi meliputi nomer lokasi, waktu, kecepatan. Pada tahap pengembangan memanfaatkan modul events pada OpenGTS untuk keperluan pertukaran data dengan format JSON. Selain itu dalam penyajian peta digital diterapkan fungsi dari Google Maps API V3 yaitu Servive DirectionsWaypoint untuk penampilan rute kendaraan dan ditambah penanda titik lokasi berdasarkan kecepatan kendaraan. Tahapan terakhir merupakan tahapan pengujian sistem, dengan menggunakan metode black box test untuk mengetahui fungsisionalitas sistem dan alpha test untuk melakukan validasi sistem dalam berbagai indikator pengujian.

\section{HASIL PENELITIAN DAN PEMBAHASAN}

Pada dalam implementasi sistem pelacak kendaraan berbasis OpenGTS dapat terbagi dalam 4 tahapan. Tahapan-tahapan meliputi hardware maupun software, diantaranya adalah sebagai berikut:

1. Analisis Kebutuhan Sistem 

2. Installasi
3. Konfigurasi
4. Pengembangan

\section{A. Analisis Kebutuhan Sistem}

Analisis kebutuhan sitem yang diperoleh dari metode pengumpulan data. Dari data-data tersebut diperoleh rumusan sistem yang akan diterapkan meliputi wilayah, pemilihan provider, dan administrasi user.

Wilayah yang diterapkan pada subjek penelitian terdapat empat batas wilayah. Batas barat diperoleh lokasi terjauh kabupaten Purworej, Jawa Tengah. Batas Utara diperoleh lokasi terjauh kabupaten Magelang Jawa Tengah. Batas Timur kabupaten Klaten, Jawa Tengah dan Kabupaten Gunungkidul, Yogyakarta. Dan batas selatan adalah sepanjang pantai selatan Kabupaten Bantul dan Kabupaten Gunungkidul. Dari batas wilayah tersebut pada sistem OpenGTS dapat difungsikan fitur Geozone seperti terlihat pada gambar. 5.

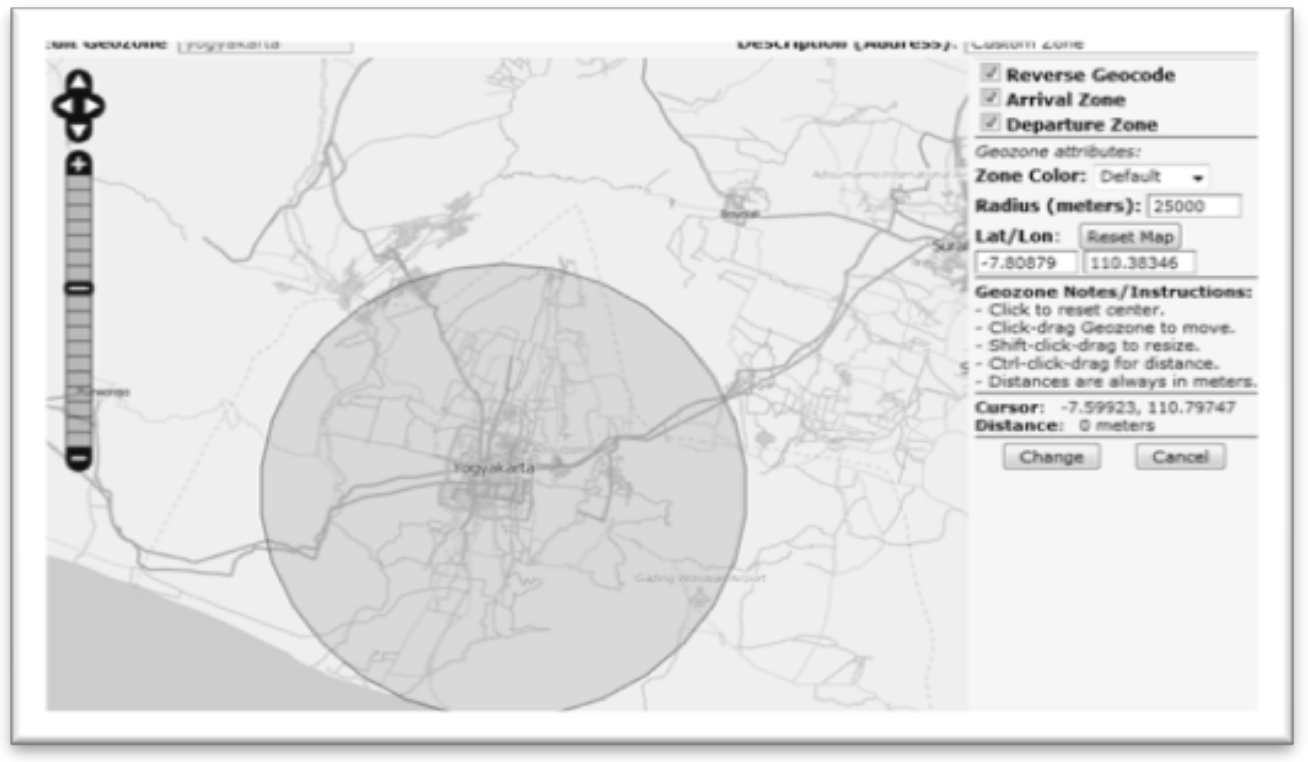

\section{Gambar.5 Geozone Yogyakarta}

Untuk provider yang digunakan dalam penelitian ini adalah provider selular GSM. 5 provider yang diuji meliput 3, Indosat, XL, Telkomsel dan Axis. Dari hasil pengujian diperoleh cakupan wilayah yang mencapai batas wilayah tersebut adalah : XL, Indosat, dan Telkomsel. Dari segi biaya dari ketiga provider yang mampu mencakup batas wilayah diperoleh nilai yang tidak begitu jauh pada setiap provider.

Administrasi user yang diterapkan pada subjek penelitian diperoleh 3 level user. Level pertama adalah Sistem Administrator, memiliki fungsi sebagai super user atau bertugas melakukan konfigurasi sistem. Level kedua adalah Admin, memiliki fungsi melakukan manajemen perangkat yang akan dilacak. Level ketiga adalah user/pengguna, memiliki fungsi melihat posisi kendaraan yang dilacak sesuai dengan kewenangan atau daerah yang dibagi.

\section{B. Installasi}

Sistem pelacak kendaraan berbasis OpenGTS diinstallasi pada sebuah VPS server.VPS server yang digunakan menggunakan vps dari Fastacenter (http://http://fastacenter.com/) dengan tipe Largetersebut terhubung dengan internet 
dan memiliki spesifikasi hardware yang digunakan untuk sistem pengujian[6]. Untuk implementasi sistem OpenGTS dapa dilihat pada gambar.6.

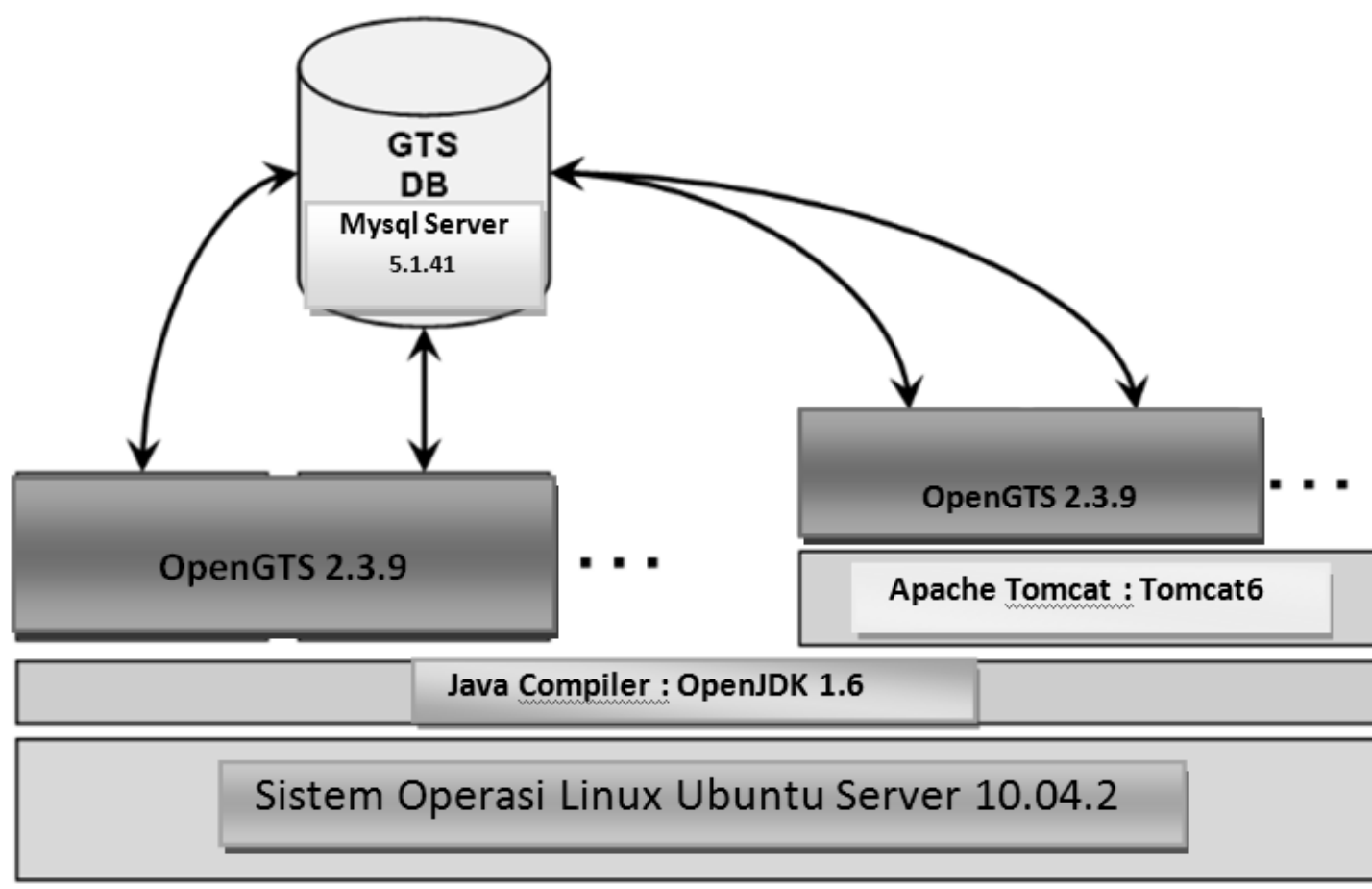

Gambar.6implementasi arsitektur sistem OpenGTS

\section{Konfigurasi}

Pada langkah konfigurasi sistem pelacak kendaraan berbasis OpenGTS dilakukan beberapa alur. Alur-alur tersebut akan memastikan sistem ataupun peralatan dapat berjalan dengan baik.Pada Gambar 7 dapat dilihat alur konfigurasi sistem pelacak kendaraan.
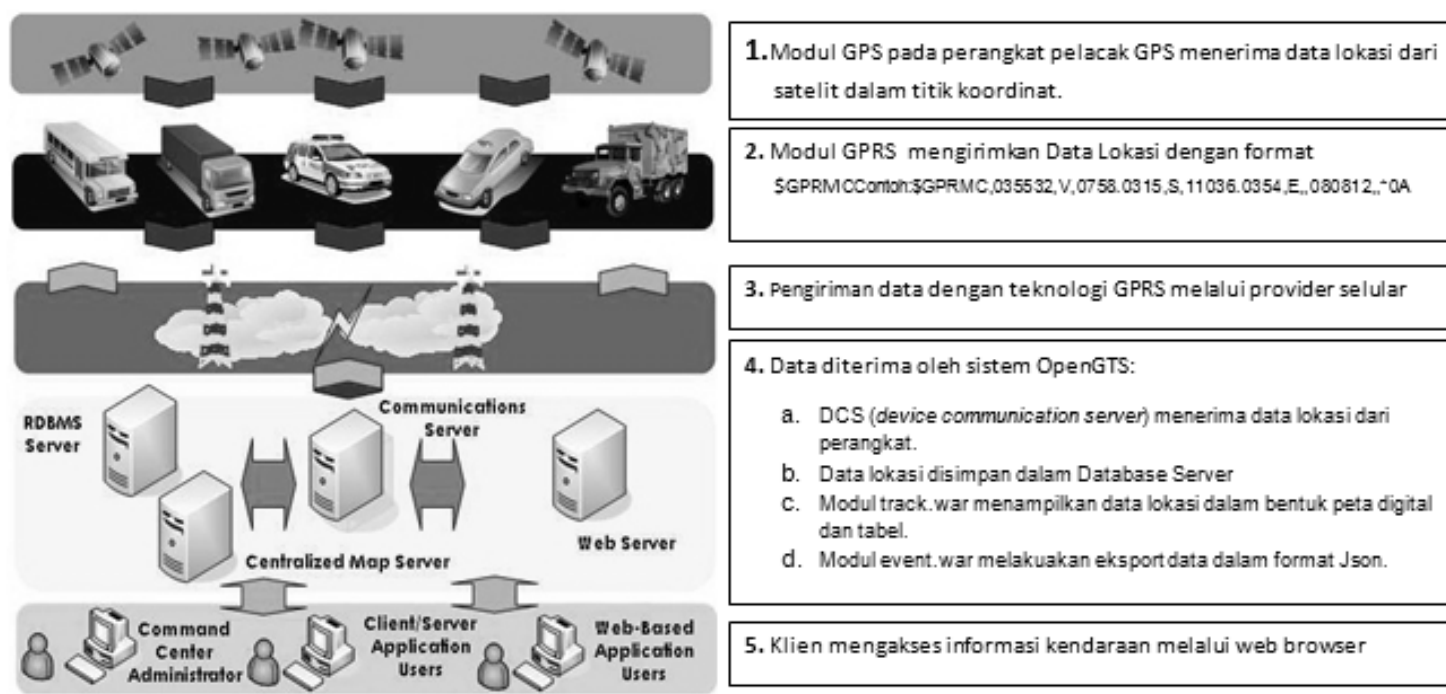

1.Modul GPS pada perangkat pelacak GPS menerima data lokasi dari satelit dalam titik koordinat.

2. Modul GPRS mengirimken Data Lokasi dengan format

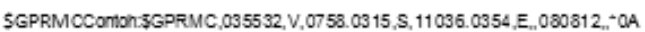

3. Pengiriman data dengan te knologi GPRS melalui provider selular

4. Data diterima oleh sistem OpenGTS:

a. DCS (device communication server) menerima data lokasi dari perangkat.

b. Data lokasi disimpan dalam Database Server

c. Modul track. war menampilkan data lokasi dalam bentuk peta digital dan tabel.

d. Modul event. war melakuakan eksport data dalam format Json.

Gambar.7 Alur konfigurasi sistem pelacak kendaraan[1]

D. Pengecekan data lokasi perangkat pelacak GPS.

Pada perangkat pelacak GPS konfigurasi harus dapat dipastikan memperolah lokasi dari satelit GPS, untuk mengetahui perangkat tersebut dapat berfungsi dengan 
baik. Untuk mendapatkan data lokasi dapat dilakukan dengan cara mengirim SMS ke nomer yang terpasang pada perangkat pelacak GPS. Untuk melakukan validasi ke akuratan data lokasi dibandingkan dengan dengan Garmin Etrex Vista HCX yang lebih presisi. Pada gambar 8 dapat dilihat cara untuk membandingkan keakuratan data lokasi.

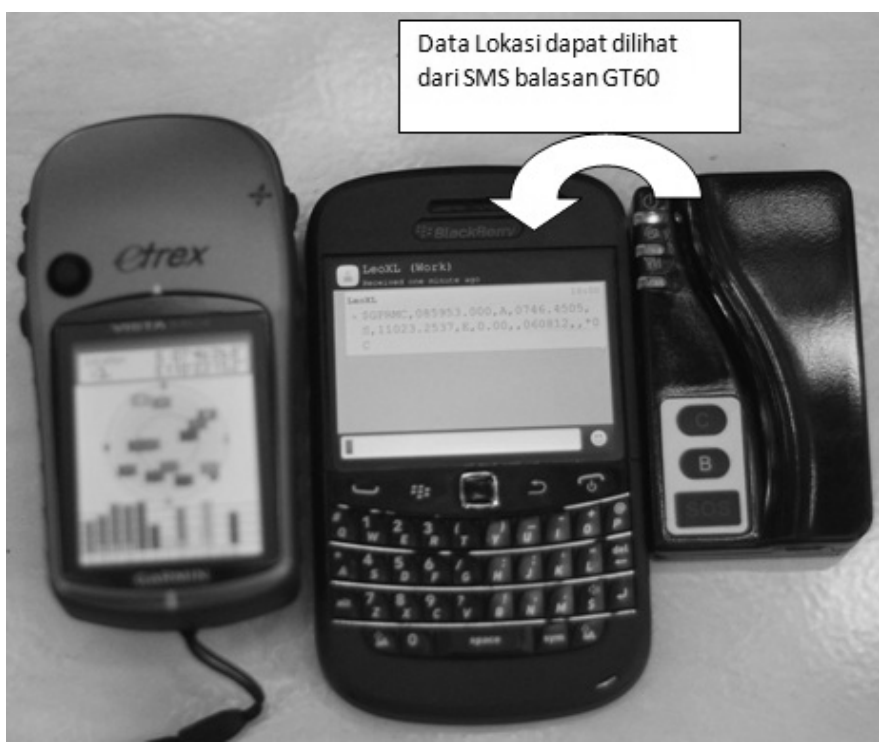

Gambar.8 Uji validasi keakuratan data lokasi.

\section{E. Konfigurasi pengiriman data lokasi perangkat pelacak GPS}

Setelah data lokasi telah diterima oleh perangkat pelacak GPS, maka sistem perlu dikonfigurasi agar dapat dikirimkan ke server melalui teknologi GPRS. Parameter yang perlu dikonfigurasi pada perangkat pelacak GPS meliputi GPRS ID, IP Server (IP VPS), Port Server, dan interval waktu pengiriman data.

\section{F. Konfigurasi OpenGTS (Pada komponen DCS)}

Karena OpenGTS belum mendukung penuh perangakat pelacak GT60, maka diperlukan konfigurasi pada komponen Device Communication Server (DCS). DCS setelah dikonfigurasi dapat menerima data yang dikirimkan oleh perangkat GT60.

File yang perlu dimodifikasi pada fileTrack Client Packet Handler.java. Bagian penting yang dilakukan modifikasi adalah pada fungsi pembacaan raw data dari data yang diterima pada bagian device communication server pada sistem opengts.

\section{ubah:}

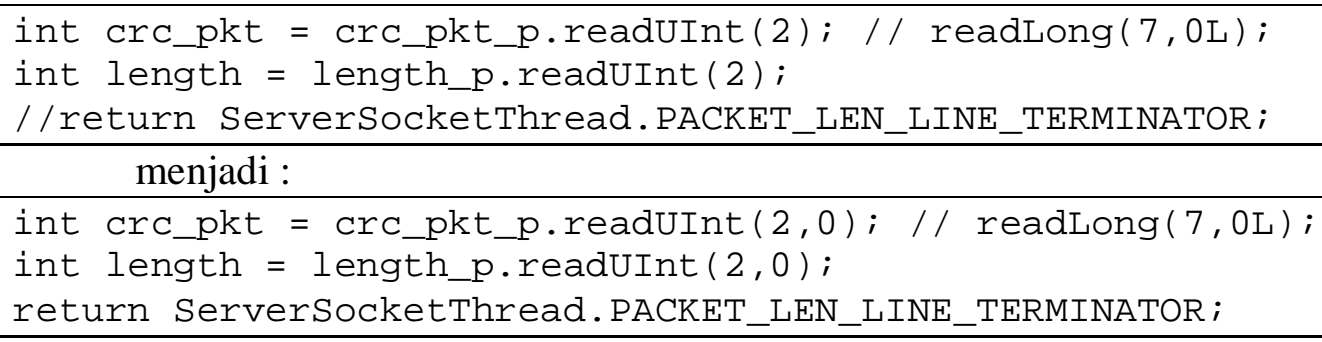

\section{G. Pengembangan sistem pelacak kendaraan}

Dari sistem OpenGTS yang sudah terinstallasi dikembangkan sistem yang digunakan dalam manajemen perusahaan. Sistem yang dikembangkan 
dengan memanfaatkan fungsi eksport data dari modul event.war dari sistem OpenGTS seperti terlihat pada gambar.9

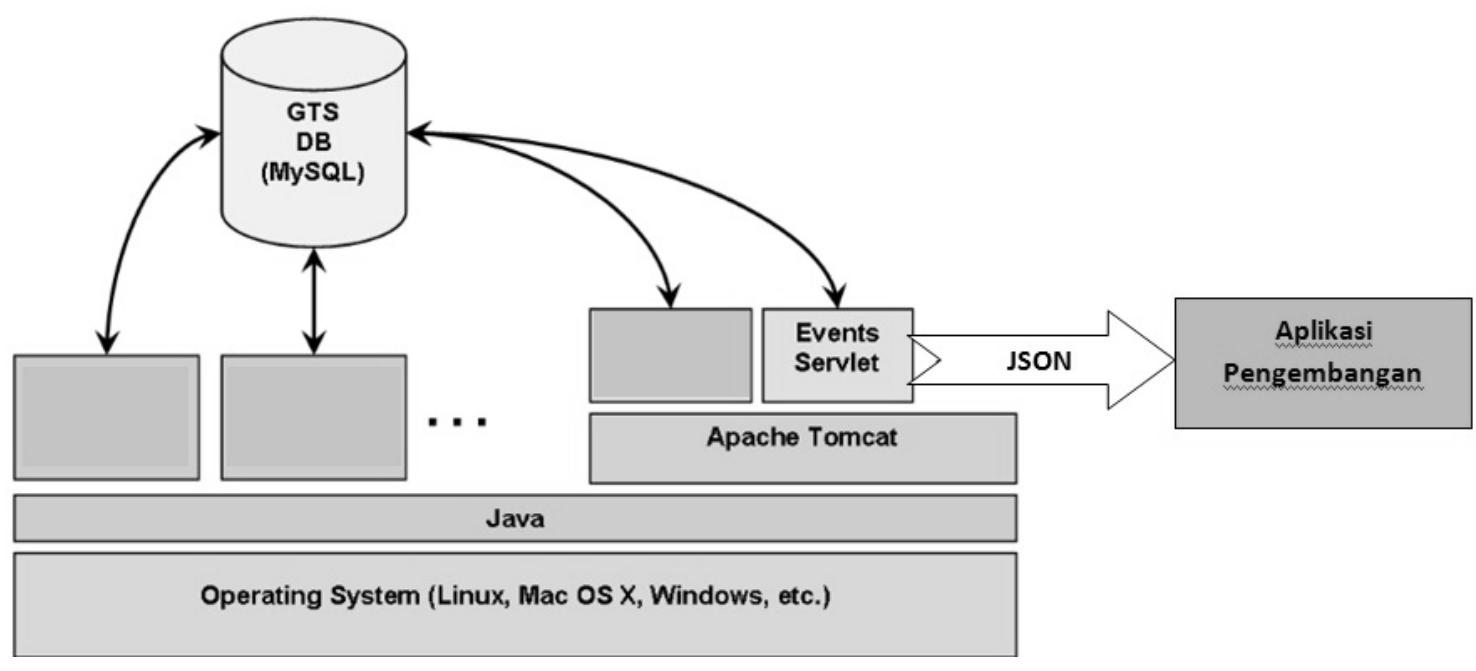

Gambar.9 arsitektur aplikasi pengembangan

Data yang diperoleh kemudian ditampilkan kembali dalam penyajian peta digital dengan ditambahkan fungsi DirectionRoute dan TravelMode mode Drivingdari Google Maps API v3. Selain itu untuk markerpada tampilan peta digital dibedakan berdasarkan kecepatan kendaraan seperti terlihat pada gambar 10 dan 11 . Selain itu informasi yang dapat diperoleh dari pada setiap titik pada marker tersebut meliputi, kecepatan kendaraan, waktu , dan urutan titik kendaraan, dan funsgi DirectionRouteseperti pada gambar 12.
0
untuk kendaraan posisi berhenti
20
untuk kendaraan dengen kecepatan 1 - 20 km/jam
50

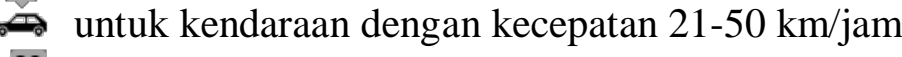
80
untuk kendaraan dengan kecepatan 51-80 km/jam
untuk kendaraan dengan kecepatan lebih besar dari 80 km/jam

\section{Gambar.10 Marker berdsarkan kecepatan}

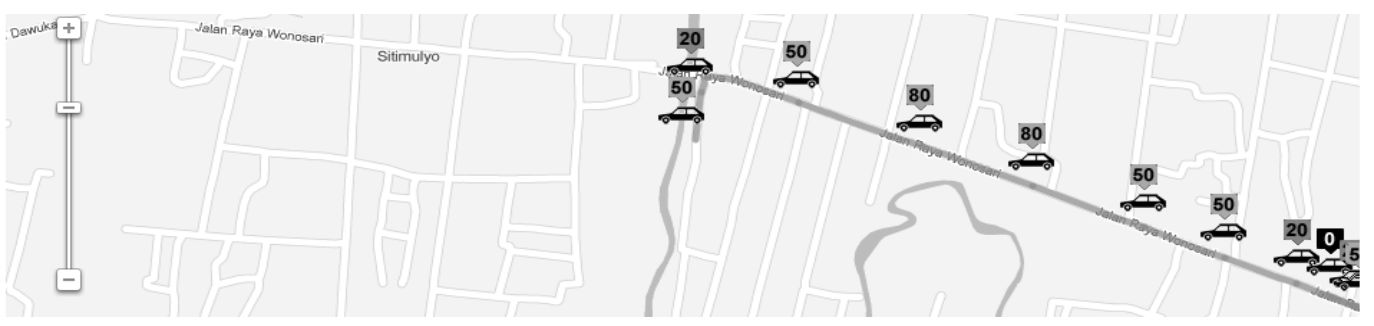

Gambar.11 Tampilan marker pada tampilan peta digital 


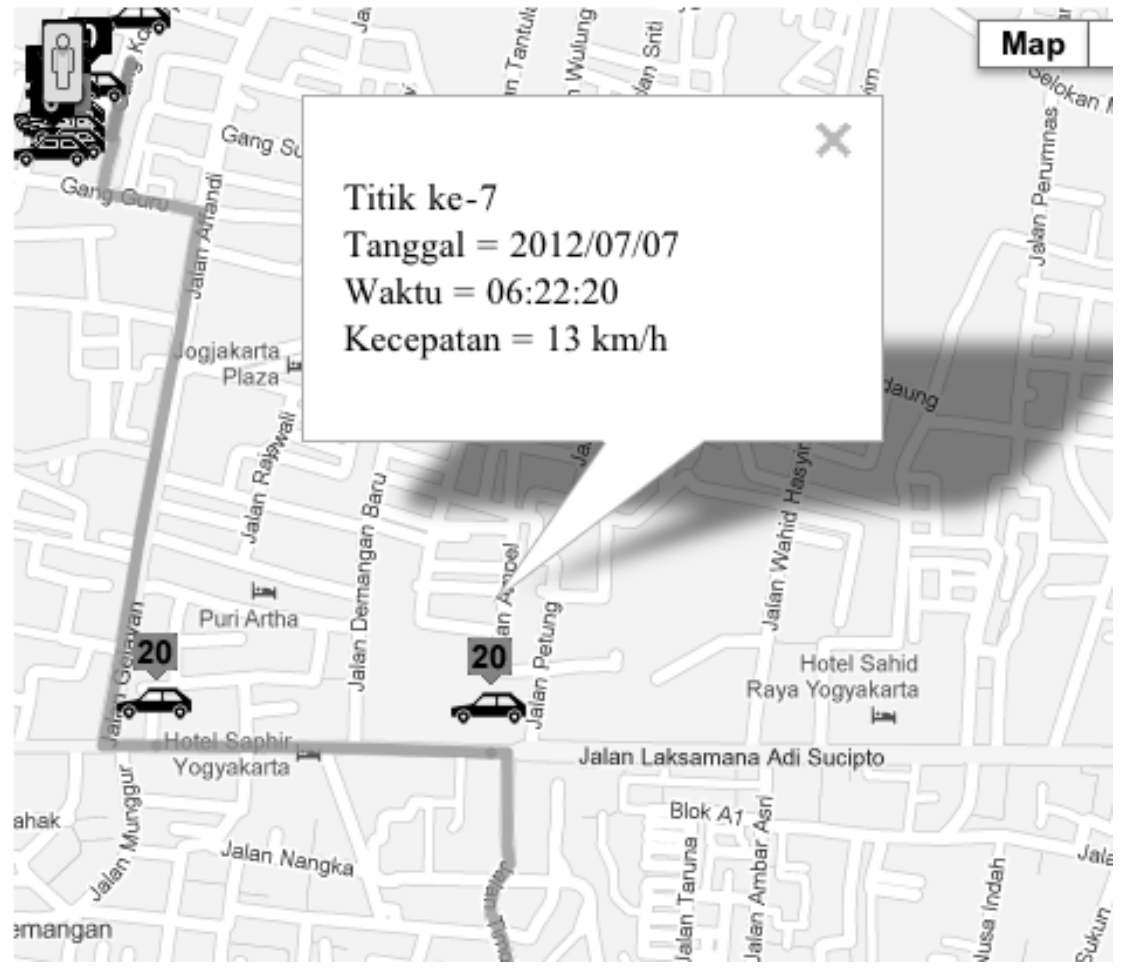

Gambar.12Tampilan rute dan marker pada aplikasi pengembangan

\section{KESIMPULAN}

Penelitian ini telah dapat menerapkan sistem pelacak kendaraan berbasis OpenGTS dengan perangkat pelacak GT60. Persiapan dalam pemiliahn provider yang digunakan merupakan tahapan penting agar sistem pelacak kendaraan dapat diterapkan dengan baik pada daerah tertentu. Pengembangan sistem pelacak GPS dengan memanfaatkan modul event.war lebih mudah dan simple untuk pengembangan aplikasi yang akan terintegrasi dengan sistem OpenGTS.

Penelitian ini masih sangat sederhana dalam penerapan fungsi DirectionRoute dan TravelingMode dari Google Map API V.3. Secara ideal fungsi tersebut dapat disatukan pada sistem OpenGTS jika sistem OpenGTS telah mendukung Google Map API V.3.

\section{DAFTAR PUSTAKA}

[1]. Anis Balaa, 2008, nal: Geographic Information System in the Vehicle Tracking and Dispatch Industry : An Applied Experience. Saudi GIS Journal http://www.saudigis.org. Diakses pada tanggal 2 Mei 2012

[2]. Ernastusti, dan Muhammad Bintang, 2006, Sistem Pelacak Kendaraan dengan teknologi GPS dan GPRS, Paper Univertisas Gunadarma

[3]. Gabriel Svennerberg,2010, Beginning Google Maps API 3, Apress

[4]. GeoTelematic Solutions, Inc.2007 The OpenGTS Project: Frequently Asked Questions, http://opengts.sourceforge.net/FAQ.html. Diakses pada tanggal 5 mei 2012

[5]. Glenn Baddeley,2001, GPS -NMEA sentence information, http:// http://aprs.gids.nl/nmea, Diakses pada tanggal 2512 Mei 2012

[6]. Google Team, 2012,Google Maps Javascript API V3 Reference (Release Version 3.8), https://developers.google.com/maps/ documentation/javascript/3.8/reference. Diakses pada tanggal 16 Juli 2012 
[7]. JSON,2012, Introducing JSON, http://www.json.org. Diakses pada tanggal 12 Juni 2012

[8]. Riyanto, 2010, Sistem Informasi Geografis, Gava Media

[9]. Yuliana Setyowati, Ahmad Syauqi Ahsan, dan Nupiah Hartatik, 2012, Aplikasi Pelacakan Mobil pada Sistem Informasi Persewaan Mobil, Paper, Politeknik Elektronika Negeri Surabaya ITS. 